\title{
Peta Pencarian Informasi Kesehatan Reproduksi Remaja Kota Bandung Berdasarkan Jenis Kelamin, Latar Belakang Pendidikan, Status Sosial dan Ekonomi
}

Nuning Kurniasih ${ }^{1}$, Neneng Komariah ${ }^{2}$

Prosiding Simposium Nasional Komunikasi Kesehatan 2015

Fikom Unpad 16 September 2016

Penerbit: Lembaga Penelitian, Pengabdian kepada Masyarakat dan Penerbitan

(LP3) Fikom Unpad

Halaman 251-268

\begin{abstract}
ABSTRAK. Makalah ini merupakan bagian dari hasil penelitian berjudul "Perilaku Pencarian Informasi Kesehatan Reproduksi Remaja : Sebuah Pemetaan Cakrawala Informasi di Kalangan Siswa SMA di Kota Bandung”. Pada makalah ini dipaparkan peta pencarian informasi kesehatan reproduksi remaja Kota Bandung berdasarkan jenis kelamin, latar elakang pendidikan, status sosial dan ekonomi siswa dengan menggunakan metode pemetaan cakrawala informasi. Metode ini diperkenalkan oleh Diane H. Sonnenwald dan Barbara M. Wildemuth dari School of Information and Library Science University of North Carolina pada tahun 2001, sebagai alternatif metode baru dalam penelitian perilaku pencarian informasi. Dalam penelitian ini, peneliti menganalisa data melalui representasi grafis dari cakrawala informasi siswa, membuat matriks sumber-sumber informasi, Focus Group Discussion (FGD) dan wawancara mendalam. Peta cakrawala informasi yang memiliki kontsruksi yang valid adalah yang memiliki derajat kesamaan yang tinggi dengan hasil wawancara dengan informan. Informan dalam penelitian ini terdiri atas tiga orang siswa yang telah mendapat materi kesehatan reproduksi di SMA, tiga orang siswa yang belum mendapatkan materi kesehatan reproduksi di SMA dan tiga siswa yang mengikuti kegiatan ekstrakulikuler yang berkaitan dengan kesehatan reproduksi, dari tiga sekolah yang sudah menjalankan dan mendapat penghargaan pada Program Sekolah Sehat. Dari tiga sekolah tersebut, dua sekolah merupakan sekolah negeri (regular) dan satu sekolah adalah sekolah swasta berasrama. Sementara para ahli yang diwawancara dalam penelitian ini adalah guru yang terkait dengan materi kesehatan reproduksi, yaitu para Guru Biologi, Guru Penjaskes, Guru Agama dan Guru BP, dari ketiga sekolah tersebut, ditambah tenaga ahli dari Dinas Kesehatan Kota Bandung. Hasil penelitian menunjukkan bahwa baik remaja putra maupun remaja putri Kota Bandung mulai mencari informasi dari adanya pengalaman inderawi berupa masalah kesehatan reproduksi yang dialami sehari-hari, namun berbeda dalam memilih sumber utama informasi terutama dikaitkan dengan sifat informasi kesehatan reproduksi yang sebagian masih dianggap tabu. Selanjutnya, remaja putra dan putri tersebut memiliki kesamaan dalam proses mendapatkan, memverifikasi, mengevaluasi, menyimpulkan serta membagi informasi yang diperolehnya hingga menghasilkan informasi atau pertanyaan yang baru. Kondisi berbeda terjadi pada siswa dengan latar belakang pendidikan, status sosial dan ekonomi menengah ke atas, dimana mereka lebih terbuka terhadap hal-hal yang dianggap tabu.
\end{abstract}

Kata Kunci : Kesehatan Reproduksi, Peta Cakrawala, Perilaku Pencarian Informasi, Putera Puteri Bandung

\footnotetext{
${ }^{1}$ Dosen Fikom Unpad, Prodi Ilmu Informasi dan Perpustakaan, nuning.kurniasih@unpad.ac.id

${ }^{2}$ Dosen Fikom Unpad,Prodi Ilmu Informasi dan Perpustakaan, nenengkomariah@ yahoo.com
} 


\begin{abstract}
This paper is a part of the research entitled "Adolescent Reproductive Health Information Seeking Behavior : An Information Horizon Mapping among Senior High School Students in Bandung City". This paper drescribed a information seeking mapping of adolescent reproductive health information of Bandung City base on gender, education, social and economic status backgraound using the information horizon mapping. This research is an Information Horizon Mapping. This method is introduced by Diane H. Sonnenwald and Barbara M. Wildemuth from School of Information and Library Science University of North Carolina in 2001, as an alternative, new method in the study of information seeking behavior. In this research, data were collected through a graphical and verbal articulation, i.e. through the horizon mapping, matrix of information resources, focus group discussion (FGD) and in-depth interviews. The validity of the horizon mapping is conducted by interviews with informants. The informants of this research are the students who got the subject of reproductive health, the students who did not get the subject of reproductive health and the students who join organization related to reproductive health in their school. The experts that interviewed for this research are teachers who teach the subject related, consisting teachers of Biology, teachers of Physical Education (Penjaskes), teachers of religion and the teachers of counseling $(B P)$ and health official from Department of Health in Bandung City. The results showed that both Bandung's boys and girls starting search the information with sensory experience such as daily reproductive health problems experienced, but they have differences in selecting the main of information source duo to the partial nature of the reproductive health information is still considered taboo. Furthermore, these boys and girls have the same process in obtaining, verifying, evaluating, concluding and sharing the information, then to generate a new information or questions. In the other hand, the students with middle to the top background in education, social and economic status, they are more open to things that are considered taboo.
\end{abstract}

Keywords: Reproductive Health, Horizon mapping, Information Seeking Behavior, Adolecent, Bandung 


\section{PENDAHULUAN}

Remaja merupakan sebuah masa peralihan dari masa anak-anak menuju dewasa. Masa remaja disebut sebagai masa yang penuh warna dimana seseorang memulai mencari jati diri dengan beragam cara. Pada masa ini, remaja rentan terhadap pengaruhpengaruh lingkungan yang menerpanya. Usia remaja ditandai dengan banyaknya perubahan pada diri remaja, baik perubahan biologis (fisik), lingkungan, psikologis hingga nilai-nilai yang dianut. Sarwono mengungkapkan bahwa pada satu sisi, remaja sedang mengalami masa transisi dari anak-anak menuju dewasa yang diikuti dengan perkembangan secara seksual, mengalami perubahan secara fisik maupun psikologis dan membuat remaja penuh rasa ingin tahu termasuk ingin tahu mengenai seks (Sarwono 2002) .

WHO mendefinisikan remaja sebagai orang-orang yang berada pada usia 10-19 tahun. Data dari WHO menunjukkan ada sekitar 350 juta orang atau sekitar 22\% penduduk Asia Tenggara pada usia tersebut. Menurut WHO jumlah ini bukanlah populasi yang homogen karena masing-masing mempunyai kebutuhan yang berbeda berdasarkan perubahan fisik, seksual, psikologis dan sosialnya. Untuk itu WHO mengembangkan empat langkah strategis untuk meningkatkan kesehatan remaja dengan berfokus pada informasi strategis, dukungan kebijakan, penguatan layanan dan penguatan kerja sama dengan sektor lainnya (SEARO WHO 2014).

Berdasarkan langkah-langkah strategis yang telah dirumuskan oleh WHO ini, peneliti tertarik untuk berperan dalam menyediakan informasi strategis perilaku pencarian informasi kesehatan reproduksi remaja di Kota Bandung yang nantinya diharapkan dapat dipergunakan sebagai bahan pertimbangan dalam menyusun kebijakan atau program advokasi kesehatan remaja, khususnya para remaja di kota Bandung.

Dari banyak masalah kesehatan remaja, perilaku kesehatan reproduksi merupakan salah satu hal yang sangat penting untuk diketahui, mengingat pada masa ini organorgan reproduksi mampu menjalani proses reproduksi. Dalam hal kesehatan reproduksi remaja, WHO mencatat (1) Sekitar 16 juta anak perempuan remaja melahirkan setiap tahun (2) Diperkirakan tiga juta anak perempuan berusia 15-19 menjalani aborsi tidak aman setiap tahun. (3) Di negara-negara berpenghasilan rendah dan menengah, komplikasi dari kehamilan dan persalinan merupakan penyebab utama kematian di kalangan perempuan usia 15-19 tahun. (4) Lahir mati dan kematian bayi baru lahir 50\% lebih tinggi diantara bayi dari ibu remaja dibandingkan pada bayi perempuan berusia 20-29 tahun. (5) Bayi dari ibu remaja lebih cenderung memiliki berat badan lahir kecil (WHO 2012). Sementara itu Laporan Rutin Program Kesehatan Ibu tahun 2013 (Direktorat Bina Kesehatan Ibu, Dirjen Bina Gizi KIA 2013) yang diterima Dinas Kesehatan Provinsi mencatat bawa Jawa Barat menduduki peringat tertinggi dalam jumlah Angka Kematian Ibu (AKI). Dari total 5019 kasus AKI, 765 kasus diantaranya terjadi di Jawa Barat, 50\% diantaranya adalah jumlah kematian ibu dan sebagian besar adalah ibu-ibu di bawah 20 tahun. Hal ini cukup mencengangkan mengingat 87,6\% persalinan telah ditangani oleh tenaga kesehatan, ini berarti kepedulian masyarakat sudah cukup tinggi, tetapi AKI masih tetap tinggi. Bahkan Hawari mengungkapkan bahwa dari 1.000.000 kasus aborsi, $60 \%$ dilakukan oleh wanita yang tidak menikah, termasuk para remaja. 70-80\% merupakan aborsi yang tidak aman, yang menjadi salah satu faktor penyebab kematian ibu, maupun komplikasi penyakit yang diderita ibu setelah melakukan aborsi (Hawari 2006).

Sebagian kalangan menilai bahwa kepedulian masyarakat dalam hal kesehatan reproduksi lebih banyak pada aspek sosial, yaitu takut menjadi pergunjingan masyarakat, sedangkan perhatian terhadap aspek yang menyangkut kesehatan reproduksi dan resiko penyakit yang diderita belum menjadi hal utama.

Beragam upaya dilakukan untuk meningkatkan kepedulian remaja terhadap kesehatannya, antara lain dengan program Genre. Program Genre digagas oleh BKKBN 
untuk membantu remaja menghadapai permasalahan hidup saat ini dan merencanakan masa depannya secara matang. Upaya lainnya adalah dengan program Sekolah Sehat yang dibina oleh puskesmas-puskesmas yang berdekatan dengan sekolah yang bersangkutan. Di Bandung, saat ini sudah banyak sekolah yang mencanangkan diri sebagai Sekolah Sehat, antara lain SMAN 2, SMAN 8, SMAN 11, SMAN 15 dan SMAT Krida Nusantara. Beberapa dari sekolah tersebut mendapat binaan dari Puskesmas setempat, antara lain SMA Negeri 11 dan 15 Bandung yang dibina oleh Puskesmas Sarijadi Bandung. Di Tingkat SMA, informasi kesehatan reproduksi menjadi bagian yang disampaikan dalam mata pelajaran antara lain Biologi, Agama, dan Pendidikan Jasmani dan Rohani. Adapun kegiatan penyuluhan yang disampaikan oleh Puskesmas Sarijadi di SMA Negeri 15 Bandung mencakup informasi kesehatan reproduksi remaja. Dengan adanya pembinaan dari instansi terkait, SMA Negeri 15 Bandung telah meraih penghargaan sebagai juara Harapan II Sekolah Sehat Tingkat Nasional pada tahun 2012 lalu. Tak jauh berbeda dengan SMA Negeri 15 Bandung, SMA Negeri 11 Bandungpun pada tahun 2014 memperoleh penghargaan sebagai sekolah Adiwiyata Tingkat Nasional. Hal ini diraih antara lain atas komitmen yang kuat dari pihak sekolah sebagai Sekolah Sehat. Siswa SMA Negeri 15 dan SMA Negeri 11 Bandung dan beberapa sekolah lain termasuk siswa yang beruntung karena dengan komitmen sekolah untuk memberikan pendidikan kesehatan reproduksi secara informal, siswa berkesempatan mendapatkan informasi kesehatan reproduksi yang tepat. Dengan kondisi itu pula, peneliti tertarik untuk meneliti perilaku pencarian informasi kesehatan reproduksi remaja di kalangan siswa SMA di Kota Bandung dengan kategori siswa di sekolah yang telah menerapkan program sekolah sehat, sekolah yang belum menerapkan program sekolah sehat dan sekolah berasrama (boarding school). Perilaku pencarian informasi kesehatan reproduksi di kalangan remaja dapat ditinjau dari berbagai hal, antara lain berdasarkan jenis kelamin, latar belakang pendidikan, status sosial dan ekonomi, seperti yang akan dipaparkan dalam makalah ini.

Dengan penelitian ini diharapkan dapat diperoleh peta pencarian informasi kesehatan reproduksi di kalangan remaja putra dan putri Bandung sehingga dapat memberikan kontribusi dalam mempertimbangkan penyusunan kebijakan atau program advokasi kesehatan remaja baik di sekolah maupun di luar sekolah. Adapun peta perilaku pencarian informasi yang diteliti didasarkan pada peta perilaku informasi yang telah disusun oleh Nuning Kurniasih dalam (Kurniasih and Komariah 2014), sebagaimana terlihat dalam Bagan 1 berikut ini :

\section{Bagan 1}

Model Perilaku Pencarian Informasi Kesehatan Reproduksi Remaja Oleh Nuning Kurniasih

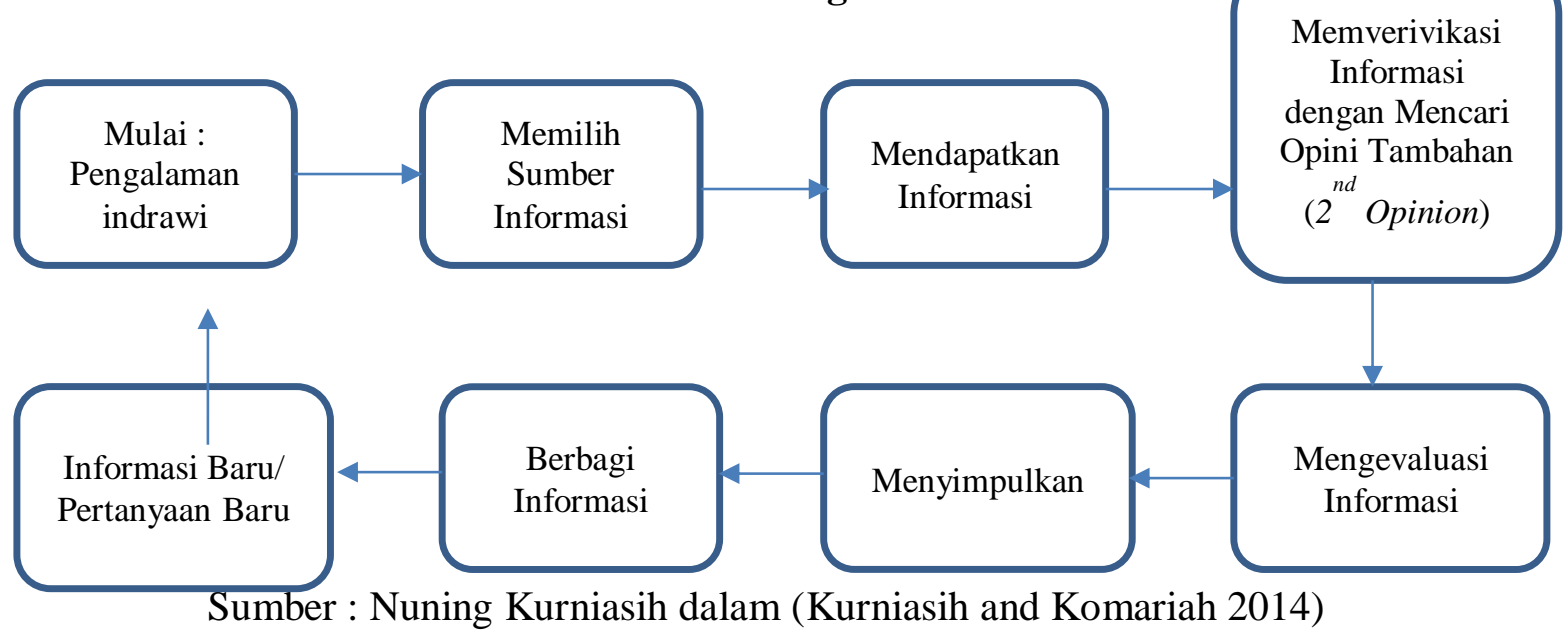


Menurut Nuning Kurniasih dalam (Kurniasih and Komariah 2014), model perilaku pencarian informasi kesehatan reproduksi remaja secara umum dilakukan melalui langkah-langkah :

1. Remaja memulai pencarian informasi kesehatan reproduksi berdasarkan apa yang dialamainya (pengalaman inderawinya).

2. Kemudian remaja memilih sumber informasi yang terjangkau, biasanya merupakan sumber informasi primer, yang langsung bisa dimintai keterangannya. Apabila tidak ada sumber informasi primer yang bisa dimintai keterangan, maka remaja akan memilih sumber informasi sekunder dan tersier.

3. Dari sumber informasi yang dipilih tersebut, remaja mendapatkan informasi.

4. Dalam banyak hal, remaja mencari sumber informasi lain $\left(2^{\text {nd }}\right.$ opinion $)$ untuk memverifikasi informasi dari sumber informasi pertama.

5. Setelah mendapatkan informasi dari sumber lain sebagai pembanding, remaja mengevaluasi informasi tersebut. Remaja dapat menilai informasi mana yang valid dan informasi mana yang tidak.

6. Remaja kemudian menyimpulkan informasi hasil evaluasi tadi sehingga mendapatkan pemahamaan yang komprehensif dari kebutuhan informasinya.

7. Remaja berbagi informasi dengan remaja lainnya. Biasanya disebarkan langsung melalui mulut ke mulut dengan teman-teman dalam satu komunitasnya, baik itu teman sekolah, teman bermain, teman satu klub, dll.

8. Dari berbagi informasi, kemudian remaja memperoleh informasi baru yang akan menjadi pengetahuan bar atau pertanyaan baru dan kembali ke awal lagi.

Sumber : Nuning Kurniasih dalam (Kurniasih and Komariah 2014)

Delapan langkah ini pula yang akan mendasari pemetaan perilaku informasi kesehatan reproduksi remaja berdasarkan jenis kelamin, latar belakang pendidikan, status sosial dan ekonomi siswa.

\section{METODE PENELITIAN}

Metode yang dipergunakan dalam penelitian ini adalah metode Pemetaan Cakrawala Pengetahuan. Metode ini diperkenalkan oleh Diane H. Sonnenwald dan Barbara M. Wildemuth dari School of Information and Library Science University of North Carolina pada tahun 2001, sebagai alternatif metode baru dalam penelitian perilaku pencarian informasi. Penelitian perilaku informasi itu sendiri biasanya menggunakan metode psikometrik, survey, wawancara, think-aloud protocols, dan observasi langsung. Menurut Sonnenwald dan Wildemuth (2001), metode-metode ini memiliki kelemahan dan kelebihan masing-masing, sebagaimana terlihat pada Tabel 1 berikut ini :

Tabel 1

Kelebihan dan Kelemahan Metode Penelitian yang Ada dalam Ilmu-ilmu Informasi

\begin{tabular}{|l|l|l|}
\hline \multicolumn{1}{|c|}{ Metode } & \multicolumn{1}{|c|}{ Kelebihan } & \multicolumn{1}{c|}{ Kelemahan } \\
\hline Psikometrik & $\begin{array}{l}\text { Menyediakan data kuantitatif } \\
\text { yang dapat dianalisis dengan } \\
\text { data statistik } \\
\text { Metode analisis; keandalan dan } \\
\text { validitas dapat ditunjukkan }\end{array}$ & $\begin{array}{l}\text { Sulit bagi tenaga kerja-intensif } \\
\text { untuk mengembangkan } \\
\text { instrumen yang handal dan valid }\end{array}$ \\
\hline $\begin{array}{l}\text { Survey dan } \\
\text { Terstruktur }\end{array}$ & $\begin{array}{l}\text { Menyediakan data kuantitatif } \\
\text { yang dapat dianalisis dengan } \\
\text { data statistik } \\
\text { metode analisis }\end{array}$ & $\begin{array}{l}\text { Data yang tidak mudah } \\
\text { menangkap } \\
\text { sifat dinamis atau kompleksitas } \\
\text { dari banyak situasi atau } \\
\text { menjelaskan perspektif } \\
\text { partisipan }\end{array}$ \\
\hline
\end{tabular}




\begin{tabular}{|l|l|l|}
\hline $\begin{array}{l}\text { Etnografi \& } \\
\text { wawancara } \\
\text { terbuka atau semi } \\
\text { terstruktur }\end{array}$ & $\begin{array}{l}\text { Pewawancara dinamis dapat } \\
\text { merespon untuk dan } \\
\text { mengajukan pertanyaan } \\
\text { tambahan dari setiap } \\
\text { pertisipan; dapat meminta } \\
\text { perspektif partisipan. }\end{array}$ & $\begin{array}{l}\text { Bisa sulit untuk mendapatkan } \\
\text { akses ke, dan kepercayaan, } \\
\text { partisipan; } \\
\text { memakan waktu untuk } \\
\text { melakukan wawancara dan } \\
\text { menganalisis data; partisipan } \\
\text { diminta untuk } \\
\text { mengingat peristiwa-peristiwa, } \\
\text { proses }\end{array}$ \\
\hline $\begin{array}{l}\text { Concurrent } \\
\text { thinkaloud } \\
\text { Protocols }\end{array}$ & $\begin{array}{l}\text { Menyediakan data tentang } \\
\text { perilaku partisipan dan } \\
\text { penalaran kognitif } \\
\text { saat melakukan tugas }\end{array}$ & $\begin{array}{l}\text { Hanya dapat diterapkan pada } \\
\text { tugas-tugas yang terjadi selama } \\
\text { periode yang relatif singkat; } \\
\text { verbalisasi } \\
\text { mungkin mengacaukan kognisi } \\
\text { atau kinerja }\end{array}$ \\
\hline $\begin{array}{l}\text { Observasi } \\
\text { Langsung }\end{array}$ & $\begin{array}{l}\text { Menyediakan data tentang } \\
\text { perilaku partisipan }\end{array}$ & $\begin{array}{l}\text { Sulit untuk mendapatkan akses } \\
\text { ke situs \& membutuhkan } \\
\text { investasi waktu yang banyak } \\
\text { untuk pengamatan; } \\
\text { tidak memberikan wawasan dari } \\
\text { perspektif atau penalaran } \\
\text { kognitif partisipan. }\end{array}$ \\
\hline
\end{tabular}

Sumber (Sonnenwald and Wildemuth 2001)

Metode Pemetaan cakrawala Pengetahuan ditawarkan atas dasar kerangka informasi manusia yang terus berkembang dan betapa pentingnya peneliti untuk terus meningkatkan pemahaman kepada para informan.

Pada penelitian ini data dikumpulkan melalui artikulasi grafis dan verbal, yaitu melalui pembuatan peta cakrawala dan wawancara mendalam. Peta cakrawala awal disusun berdasarkan hasil studi pustaka, observasi dan focus group discussion (FGD). Setelah peta cakrawala tersusun, kemudian dilakukan wawancara terhadap para informan untuk menguji validitas dari peta cakrawala tersebut. Peta cakrawala informasi yang memiliki kontsruksi yang valid adalah yang memiliki derajat kesamaan yang tinggi dengan hasil wawancara dengan informan.

Adapun analisa data penelitian dilakukan melalui tahapan :

1. Menganalisa representasi grafis dari cakrawala informasi siswa.

2. Membuat matriks sumber-sumber informasi.

3. Klarifikasi dengan mewawancara informan.

Penelitian ini dilaksanakan di tiga sekolah di Kota Bandung yang telah melaksanakan Program Sekolah Sehat yaitu SMA Negeri 11, SMA Negeri 15 dan SMAT Krida Nusantara Bandung. Informan dari setiap sekolah dipilih dengan kriteria sebagai berikut:

1. Siswa yang telah mendapatkan Materi Kesehatan Reproduksi pada Mata Pelajaran Biologi (Kelas 11), 3 orang dari setiap sekolah, jumlah 9 siswa.

2. Siswa yang mengikuti kegiata ekstrakulikuler terkait masalah kesehatan reproduksi, seperti UKS, KKR dan Keputrian, 3 orang dari setiap sekolah, jumlah 9 siswa.

3. Siswa yang belum mendapat Materi Kesehatan Reproduksi pada Mata Pelajaran Biologi (Kelas 10), 3 orang dari setiap sekolah, jumlah 9 siswa.

Dengan demikian informan dalam penelitian ini berjumlah 27 orang. 
Selain itu triangulasi dilakukan dengan guru-guru terkait Materi Kesehatan Reproduksi, yaitu :

1. Guru Biologi, 1 orang dari setiap sekolah, jumlah 3 guru.

2. Guru Agama, 1 orang dari setiap sekolah, jumlah 3 guru.

3. Guru Pendidikan Jasmani, 1 orang dari setiap sekolah, jumlah 3 guru.

4. Guru Bimbingan Konseling (BK), 1 orang dari setiap sekolah, jumlah 3 guru.

5. Dua orang ahli dari Dinas Kesehatan Kota Bandung, yaitu Kasi Yankes Khusus dari Program Anak dan Remaja Seksi Yankes Khusus.

Dengan demikian, triangulasi dilakukan terhadap 14 ahli yang berhubungan dengan materi Kesehatan Reproduksi Remaja.

\section{HASIL DAN ANALISA}

\section{Peta Pencarian Informasi Kesehatan Reproduksi Remaja Putri Kota Bandung}

Berikut adalah perilaku pencarian informasi kesehatan reproduksi remaja putri di Kota Bandung :

1. Informan putri memulai pencarian informasi kesehatan reproduksi biasanya berdasarkan masalah kesehatan reproduksi yang dialami sehari-hari, seperti menstruasi dan keputihan atau keingintahuan terhadap sesuatu.

2. Sumber informasi yang dipilih oleh informan putri adalah :

a. Ibu atau saudara perempuan sebagai sumber informasi utama untuk masalah kesehatan reproduksi. Ibu atau saudara perempuan dipilih sebagai sumber informasi utama karena remaja putri merasa dekat dengan Ibu dan saudara peremuan. Mereka mengatakan bahwa mereka dapat secara terbuka mengungkapkan masalah kesehatan reproduksinya kepada Ibu atau saudara perempuan. Namun demikian, hal-hal yang dianggap tabu atau sensitif untuk ditanyakan kepada orang tua, mereka memilih sumber informasi lain. Informan memahami apabila sebagian orang tua masih menganggap mereka terlalu dini untuk mengetahui hal-hal yang dianggap tabu tersebut dan belum saatnya mengetahui tentang hal itu.

b. Sumber informasi berikutnya yang juga menjadi rujukan adalah guru, terutama guru perempuan pada mata pelajaran Biologi, Penjaskes, Agama dan BP. Siswa perempuan akan bertanya lebih terbuka kepada guru perempuan dan cenderung menahan diri karena malu apabila gurunya laki-laki..

c. Selain orang tua dan guru, remaja putri Kota Bandung juga suka bercerita dan berbagi informasi tentang kesehatan reproduksi kepada teman-temannya.

d. Sumber informasi lainnya yang dipergunakan adalah dengan menelusur di internet, terutama melalui blog yang dihasilkan melalui penelusuran di google. Berkaitan dengan sumber informasi yang ada di dalam blog, siswa mengakui kalau kadang-kadang mereka bingung karena ada informasi yang berbeda dari setiap blog. Untuk meyakinkan informasi mana yang benar, siswa biasanya membaca lebih dari satu blog dan apabila ada kesamaan informasi dari blog-blog yang ditemukan, maka informasi tersebut yang dianggap benar. Selain blog, Youtube juga menjadi pilihan para siswa dalam mencari informasi kesehatan reproduksi.

e. Informan putri membaca majalah atau surat kabar, majalah atau komik remaja yang dilanggan oleh orang tuanya. Biasanya mereka membaca khusus informasi kesehatan reproduksi yang mereka butuhkan atau isu-isu yang sedang hangat di masyarakat.

f. Penggunaan perpustakaan sebagai sumber informasi oleh informan putri hanya untuk membaca buku-buku teks berkaitan dengan mata pelajaran. Di 
beberapa perpustakaan dipasang poster yang dikeluarkan oleh Dinas Kesehatan dan siswa cukup memahami makna dari gambar atau tulisan yang ada di dalam poster tersebut.

g. Iklan, acara televisi dan film yang menayangkan kesehatan reproduksi hanya kadang-kadang ditonton oleh informan putri.

h. Informan putri yang mengikuti ekstrakulikuler yang berkaitan dengan kesehatan biasanya memiliki pengetahuan lebih dulu dan lebih banyak tentang kesehatan reproduksi dibandingkan dengan informan yang tidak mengikuti ektrakulikuler tersebut.

i. Apabila terserang sakit, barulah informan putri menghubungi dokter atau tenaga kesehatan.

3. Informan putri biasanya mencari informasi kesehatan reproduksi dari satu sumber.

4. Untuk memverifikasi informasi dari sumber tadi, informan putri biasanya mencari informasi tambahan ( $2^{\text {nd }}$ opinion) dari sumber informasi lain.

5. Informan putri melakukan evaluasi informasi dengan menganalisa dan menilai semua jenis informasi yang diperolehnya. Informasi yang dianggap punya banyak kesamaan, dianggap sebagai informasi yang benar.

6. Informan putri menyimpulkan informasi setelah mendapatkan jawaban dari informasi kesehatan reproduksi yang dicari/dibutuhkannya.

7. Informan putri biasanya berbagi informasi dengan teman sekolah/teman sepermainan. Hal ini juga dibenarkan oleh narasumber triangulasi, bahwa remaja secara umum lebih suka merbagi informasi yang menyangkut kesehatan reproduksi dengan teman dalam komunitasnya.

8. Dari keseluruhan proses tersebut, biasanya informan putri dapat menghasilkan informasi atau pertanyaan baru.

Secara singkat, peta perilaku informasi kesehatan reproduksi remaja putri Kota Bandung tersebut dapat digambarkan sebagai berikut : 


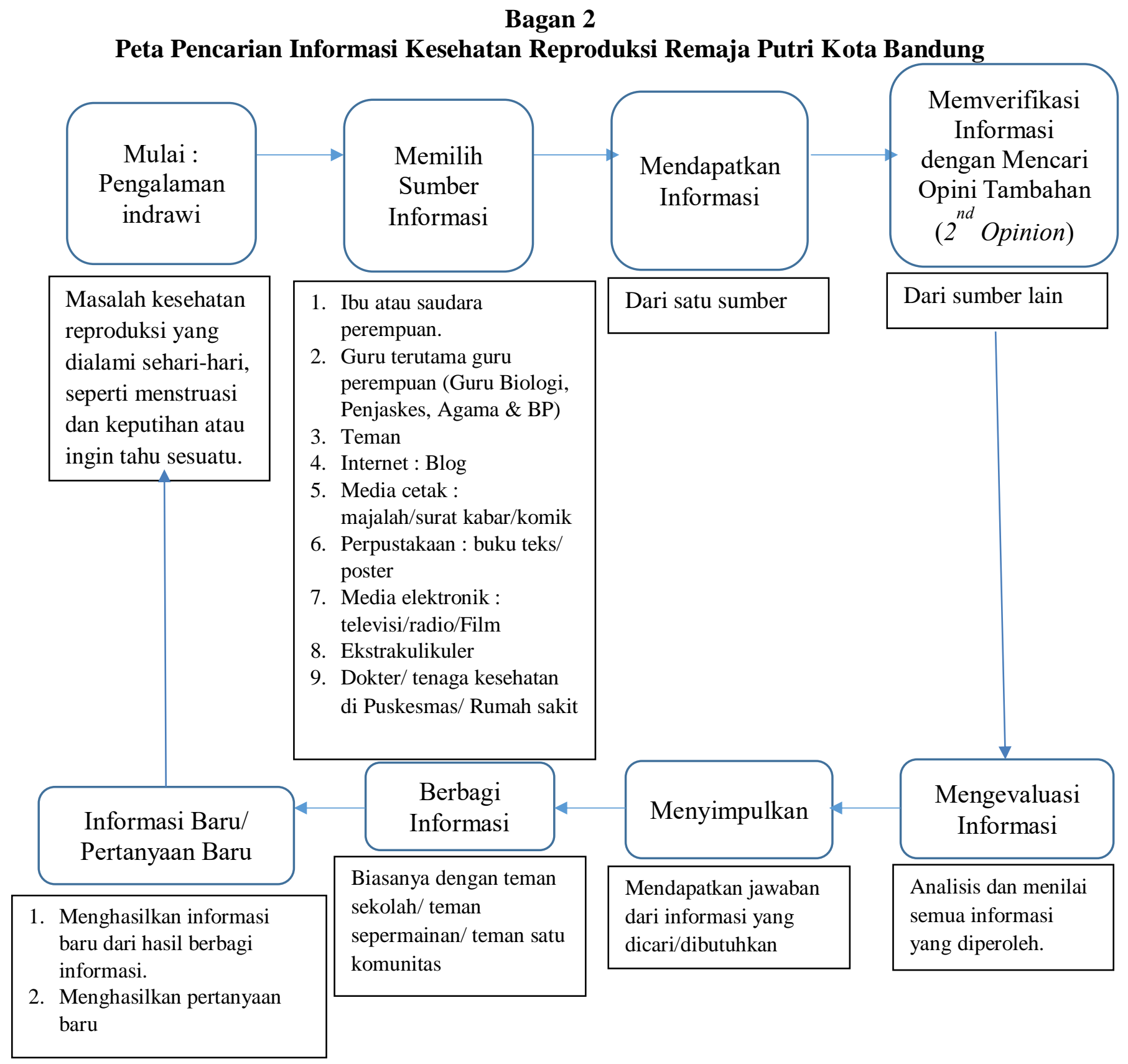

\section{Adaptasi dari Model Perilaku Pencarian Informasi Kesehatan Reproduksi Remaja Oleh Nuning Kurniasih}

\section{Peta Pencarian Informasi Kesehatan Reproduksi Remaja Putra Kota Bandung}

Berikut adalah perilaku pencarian informasi kesehatan reproduksi remaja putri di Kota Bandung :

1. Sebagaimana informan putri, informan putra mulai mencari informasi kesehatan reproduksi berdasarkan pada masalah kesehatan reproduksi yang dialaminya sehari-hari, seperti mimpi basah atau hanya ingin mengetahui tentang sesuatu.

2. Berbeda dengan informan putri yang lebih terbuka kepada Ibu atau saudara perempuan, informan putra lebih memilih internet, baik melalui blog maupun Youtube sebagai informasi utama dalam hal pencarian informasi kesehatan reproduksi. Berikut adalah sumber informasi informan pria berdasarkan urutannya : 
a. Informan putra biasanya mencari informasi kesehatan reproduksi melalui internet. Alasan informan putra menggunakan internet sebagai sumber informasi utama untuk masalah kesehatan reproduksi adalah karena penggunaan internet dinilai lebih pribadi dan dapat secara bebas mencari informasi-informasi yang sifatnya tabu atau sensitif.

b. Informan putra lebih terbuka kepada guru dibandingkan dengan informan putri. Mereka terbuka baik kepada guru laki-laki maupun perempuan.

c. Sumber informasi berikutnya adalah teman. Biasanya para informan bercerita tentang pengalaman dan pengetahuannya tentang kesehatan reproduksi.

d. Sebagaimana informan putri, informan putra juga membaca majalah atau surat kabar atau komik remaja yang dilanggan oleh orang tuanya. Biasanya mereka membaca khusus informasi kesehatan reproduksi yang mereka butuhkan atau isu-isu yang sedang hangat di masyarakat.

e. Sebagaimana informan putri, informan putra juga menggunakan perpustakaan sebagai sumber informasi untuk membaca buku-buku teks berkaitan dengan mata pelajaran dan melihat poster yang dipasang di sana.

f. Iklan, acara televisi dan film yang menayangkan kesehatan reproduksi juga hanya kadang-kadang ditonton informan putra.

g. Informan putra yang mengikuti ekstrakulikuler yang berkaitan dengan kesehatan biasanya memiliki pengetahuan lebih dulu dan lebih banyak tentang kesehatan reproduksi dibandingkan dengan informan yang tidak mengikuti ektrakulikuler tersebut. Kondisi ini sama dengan yang terjadi pada informan putri.

h. Informan putra jarang bertanya kepada orang tua, baik ayah maupun ibu tentang masalah kesehatan reproduksi karena tidak ingin dicurigai orang tua. Namun demikian, sekali-sekali mereka masih bertanya kepada orang tua atau saudara perempuannya.

i. Informan putra biasanya baru akan menghubungi dokter atau tenaga kesehatan ketika terserang sakit dan memerlukan penanganan dokter atau tenaga kesehatan lainnya.

3. Untuk proses mendapatkan informasi, memverifikasi, mengevaluasi, menyimpulkan, berbagi informasi dan informasi baru/pertanyaan baru yang dihasilkan, pada dasarnya sama dengan yang dilakukan oleh informan putri. Hal ini secara singkat dapat digambarkan sebagai berikut : 
Bagan 3

Peta Pencarian Informasi Kesehatan Reproduksi Remaja Putra Kota Bandung

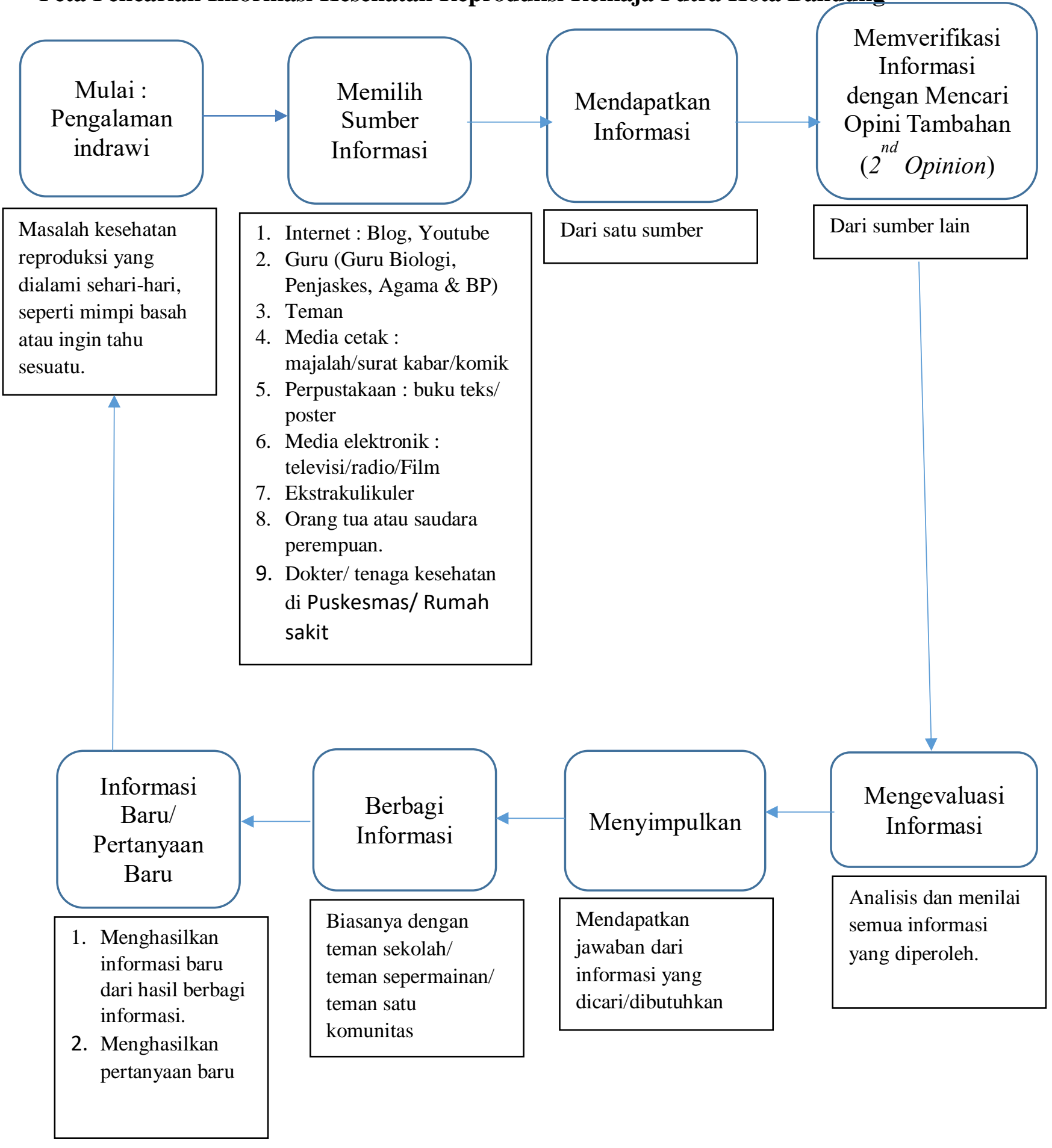

\section{Adaptasi dari Model Perilaku Pencarian Informasi Kesehatan Reproduksi Remaja Oleh Nuning Kurniasih}

\section{Perilaku Pencarian Informasi Kesehatan Reproduksi Remaja berdasarkan Latar Belakang Pendidikan, Status Sosial dan Ekonomi}

Secara singkat perilaku pencarian informasi kesehatan reproduksi remaja berdasarkan latar belakang pendidikan, status sosial dan ekonomi dapat digambarkan sebagai berikut : 


\section{Bagan 4 \\ IV. Peta Pencarian Informasi Kesehatan Reproduksi Remaja Remaja berdasarkan Latar Belakang Pendidikan, Status Sosial dan Ekonomi}

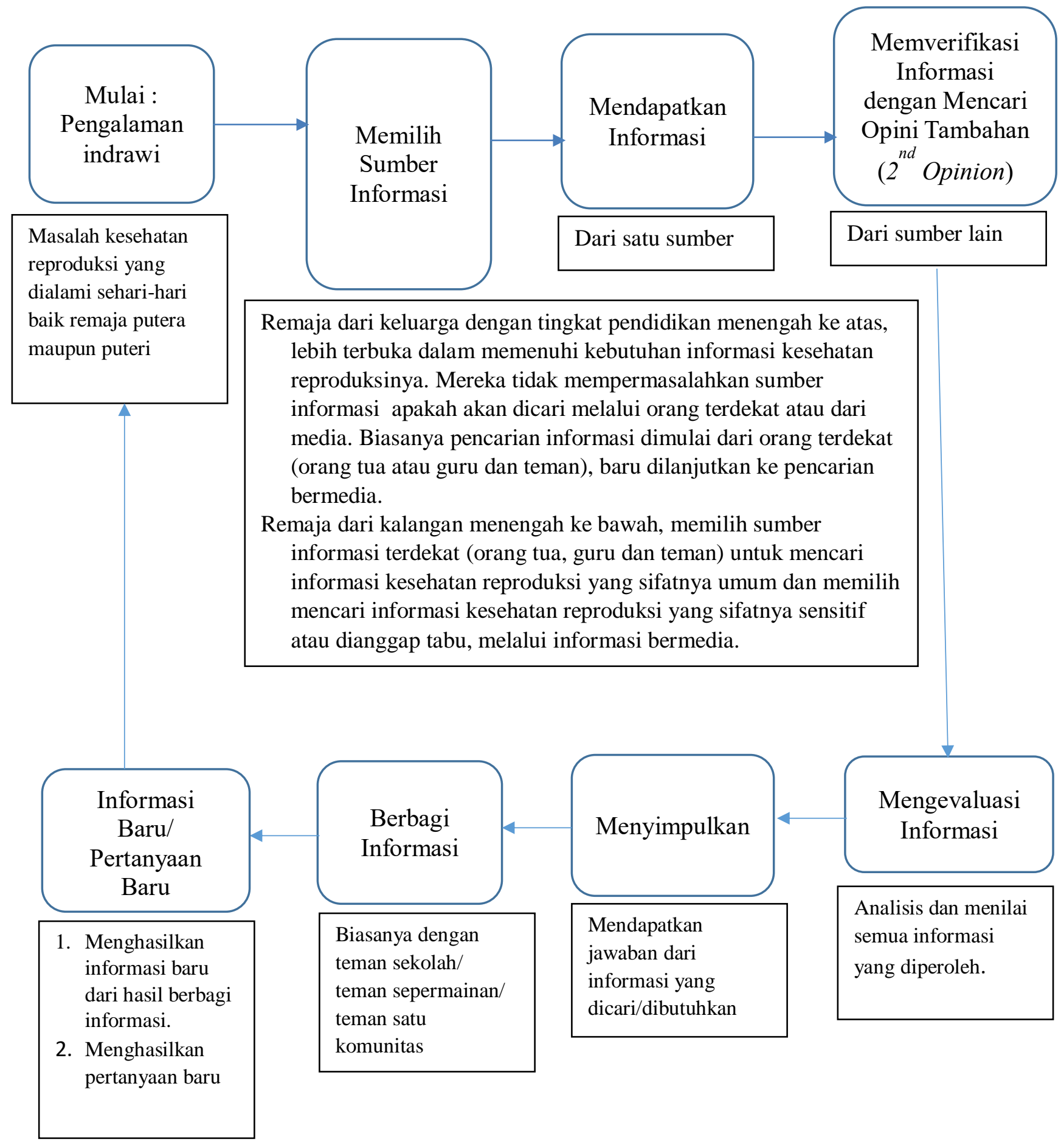

Adaptasi dari Model Perilaku Pencarian Informasi Kesehatan Reproduksi Remaja

Oleh Nuning Kurniasih

Dari bagan tersebut dapat dilihat bahwa perbedaan perilaku pencariaan informasi dengan latar belakang pendidikan, sosial dan ekonomi yang berbeda terletak pada pemilihan sumber-sumber informasinya. Remaja dari keluarga dengan tingkat pendidikan menengah ke atas, lebih terbuka dalam memenuhi kebutuhan informasi kesehatan reproduksinya. Mereka tidak mempermasalahkan sumber informasi apakah akan dicari melalui orang terdekat atau dari media. Biasanya pencarian informasi 
dimulai dari orang terdekat (orang tua atau guru dan teman), baru dilanjutkan ke pencarian bermedia.

\section{KESIMPULAN}

1. Perilaku pencarian informasi kesehatan reproduksi oleh remaja baik putra maupun putri adalah melalui tahap-tahap sebagai berikut :

a. Mulai dari identifikasi kebutuhan informasi berdasarkan pengalaman inderawi.

b. Memilih sumber informasi

c. Mendapatkan informasi

d. Memverifikasi informasi dengan menccari informasi tambahan ( $2^{\text {nd }}$ opinion $)$

e. Mengevaluasi informasi

f. Menyimpulkan

g. Berbagi informasi

h. Menghasilkan informasi atau pertanyaan baru.

2. Perbedaan perilaku antara pelajar putra dan pelajar putri adalah pada pengalaman inderawi laki-laki dan perempuan yang berbeda dan dalam pemilihan sumber-sumber informasi. Pelajar puteri lebih memilih sumber informasi dari keluarga, guru dan teman sebagai sumber informasi utama, sedangkan pelajar putera lebih memilih internet, baru kemudian guru dan teman. Pelajar laki-laki umumnya kurang terbuka atau jarang bertanya tentang kesehatan reproduksi kepada keluarga.

3. Kondisi berbeda terjadi pada siswa dengan latar belakang pendidikan, status sosial dan ekonomi menengah ke atas, dimana mereka lebih terbuka terhadap hal-hal yang dianggap tabu. Mereka, baik putra maupun putri, lebih memilih keluarga sebagai sumber informasi utama, baru kemudian guru dan teman. Apabila siswa dari latar belakang pendidikan, tingkat status sosial dan ekonomi keluarga menengah ke bawah, memilih menelusur secara diam-diam informasiinformasi yang dianggap tabu atau sensitif, maka siswa dari latar belakang keluarga dengan tingkat pendidikan, status sosial dan ekonomi lebih tinggi, melakukannya secara terbuka, tidak malu-malu.

4. Hasil penelitian ini diharapkan dapat memberikan kontribusi dalam pertimbangan penyusunan kebijakan atau program advokasi kesehatan reproduksi remaja baik di sekolah maupun di luar sekolah.

Daftar Pustaka

Asamani, Jamal Ma'mur. Kiat Mengatasi Kenakalan Remaja di Sekolah. Jogjakarta: BUKUBIRU, 2012.

Departemen Kesehatan. Undang-Undang Kesehatan RI Nomor 36 Tahun2009 tentang Kesehatan. 2009. http://www.depkes.go.id/downloads/UU_No._36_Th_2009_ttg_Kesehatan.pdf.

Developing National Quality Standars for Adolescent Friendly Health Service. Developing standards and accompanying elements of a standards-driven quality improvement initiative. WHO, 2012.

Direktorat Bina Kesehatan Ibu, Dirjen Bina Gizi KIA. Laporan Akuntabilitas Kinerja Direktorat Bina Kesehatan Ibu Tahun 2013. pdf http://www.gizikia.depkes.go.id/download/LAKIP-DIT-IBU-TAHUN2013.pdf., Jakarta: Depkes, 2013.

Ermawati, Ristie, and Rifki Aziz. Sikat Habis Biologi SMA/MA Kls X, XI, XII. Jakarta: Kompas Ilmu, 2013.

Hadziq, Khairul. Pendidikan Jasmani Olah Raga dan Kesehatan untuk SMA-MA/SMK Kelas XI. Bandung: Yrama Widya, 2013. 
Hawari, Dadang. Penyalahgunaan dan Ketergantungan NAPZA edisi ke:2. Jakarta: FK UI, 2006.

Imron, Ali. Pendidikan Kesehatan Reproduksi Remaja- Peer Educator \& Efektivitas Program PIK-KRR di Sekolah. Yoyakarta: ArRuzz Media, 2012.

KamusBahasaIndonesia.org. Kamus Bahasa Indonesia Online. n.d. http://kamusbahasaindonesia.org/sehat/mirip (accessed Mei 20, 2014).

Kurniasih, Nuning, and Neneng Komariah. Perilaku Pencarian Informasi Kesehatan Reproduksi Remaja : Sebuah Pemetaan Cakrawala Informasi di Kalangan Siswa SMA di Kota Bandung. Laporan Penelitian DIPA PNBP Unpad, 2014: Fikom Unpad, 2014.

Notoatmodjo. Pendidikan dan Perilaku Kesehatan. Jakarta: Rineka Cipta, 2007.

Nurcahyani, Dwi Indah. Pengetahuan Remaja soal Masa Subur Masih Rendah. November 7 , 2013. http://health.okezone.com/read/2013/11/07/482/893133/pengetahuan-remajasoal-masa-subur-masih-rendah (accessed April 2014, 3).

Nurhayati, Nunung, Syaiful Azmi, and Teti Suryati. Biologi SMA/MA Kelas XI : Kelompok Peminatan Matematika dab Ilmu-ilmu Alam (2). Bandung: Yrama Widya, 2013.

-. Buku Guru Biologi untuk Kelas XI : Kelompok Peminatan Matematika dan Ilmuilmu Alam (2). Bandung: Yrama Widya, 2013.

Nurlailah. Pendidikan Agama Islam dan Budi Pekerti untuk SMA/SMK Kelas X. Bandung: Yrama Widya, 2013.

Sarwono, S.W. Psikologi Sosial. Jakarta: Balai Pustaka, 2002.

SEARO WHO. Adolescent Health. 2014. http://www.searo.who.int/topics/adolescent_health/en/ (accessed April 25, 2014).

- Adolescent Health and Development. 2014. http://www.searo.who.int/entity/child_adolescent/topics/adolescent_health/en/ (accessed April 25, 2014).

Sonnenwald, Diane H., and Barbara M. Wildemuth. Investigating Information Seeking Behavior Using the Concept of Information Horizons. Conference Paper, ALISE 2001 Methodology Paper Award Winner, NC: University of North Carolina, 2001.

Teaching \& Learning Services University of Maryland Libraries . Primary, Secondary and Tertiary Sources. 3 2, 2014. http://www.lib.umd.edu/t1/guides/primarysources (accessed 11 15, 2014).

WHO. Adolescent Pragnancy. Mei 2012. http://www.who.int/mediacentre/factsheets/fs364/en/ (accessed April 30, 2014).

Wilson, T.D. Human Informastion behaviour. 2000. http://inform.nu/Articles/Vol3/v3n2p49-56.pdf (accessed Mei 20, 2012).

- Information behaviour, an interdisciplinary perspective. 1996. http://www.informationr.net/tdw/publ/infbehav/chap2.html (accessed Desember 3, 2013). 


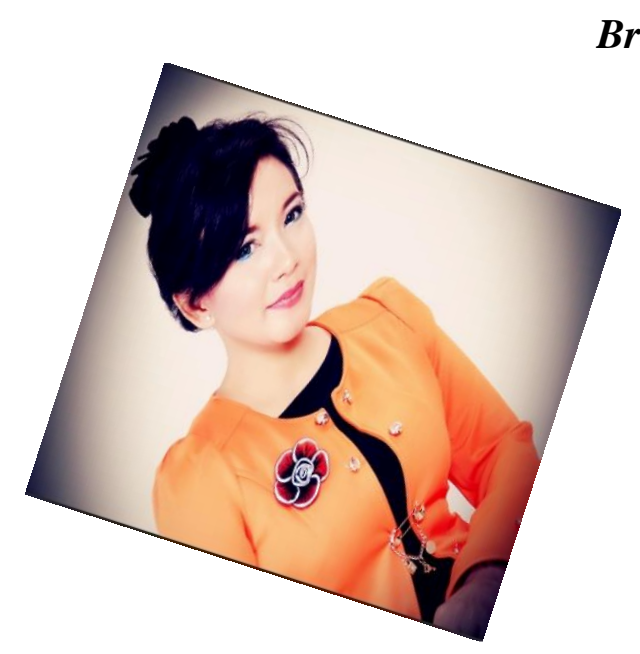

Brief of Biography

Nuning Kurniasih holds Master degree in Library and Information Science from Univesitas Indonesia. She joined the project on Historical Archive for Human Evolution and Development at Leiden University, Netherlands in 2011. She started her career in 2000 as Lecturer and Researcher at Padjadjaran University (Unpad), Bandung, Indonesia, where she served as Secretary of Public Relations, Head of Computer Laboratory etc and currently is heading the Computer Mediated Communication Laboratory at Faculty of Communication Science. She is representing Indonesia in the Editorial Board of ELIS (1996-now) and was as Country Coordinator in International Librarian Network (ILN in 2014). Her research interest are Information Economics, Social Media, Information Retrieval, Digital and Cultural Literacy, Health Information, Informatics/Altmetrics, Digital Archiving and ICT application for knowledge management. She achieved "The Top Conference Paper Myung-Seok Park Award" from Pacific and Asian Communication 